\title{
The Mediating Effects of Infant Teachers' Sensitivity on the Relationship Between Play-Teaching Efficacy and Infants' Childcare Center Adjustment
}

\author{
Yoonse Hwang \\ Professor, Department of Eaely Childhood Education, Kangwon National University, Kangwon, Korea \\ 놀이 교수효능감과 영아의 어린이집 적응의 관계에서 \\ 영아 교사 민감성의 매개효과 \\ 황윤세 \\ 강원대학교 유아교육과 교수
}

Objectives: This study examines the relationship of play-teaching efficacy, and infants' child care center adjustment to investigate the mediating effect of infant teachers' sensitivity.

Methods: Using the questionnaire survey method targeting 399 infant teachers working at child care centers in Gyeonggi and Kangwon Province, this study aimed to measure play-teaching efficacy and infant teachers' sensitivity, and examine these factors' effects on the infants' child care center adjustment.

Results: Infant teachers' sensitivity partially mediated the relationship between play-teaching efficacy and infants' child care center adjustment.

Conclusion: In addition to having direct effect on infants' childcare center adjustment play-teaching efficacy has indirect effects on it through the mediation of infant teachers' sensitivity.

Keywords: infant teachers' sensitivity, play-teaching efficacy, child care center adjustment

\section{Introduction}

현대사회의 주요한 논쟁인 인구 문제 그리고 이와 맞물린 저 출산 및 자녀양육에 대한 이슈는 사적 차원이 아닌 공적 차원 으로 패러다임이 변화되었다. 이러한 양육 패러다임에서는 더 어린시기에 어린이집 생활의 시작하므로 더욱 질 높은 보육이 필요하다.

또한 우리나라의 경우, 2012년 영아 무상보육 확대로 인해 어린이집 이용 영아 수가 급증하였다. 영아보육은 이제 우리 사회의 보편적인 현상으로 자리 잡았으며, 어린 시기에 사회 생활에 적응해야 하는 과제를 안고 있다. 이후에도 국가 정책

Corresponding Author: Yoonse Hwang, Professor, Department of Eaely Childhood Education, Kangwon National University, KNU Samcheok Campus, 346 Jungang-ro, Samcheok-si, Gangwon-do, 25913 Korea E-mail: yshwang@kangwon.ac.kr
과 부모의 양육관 변화 등 다양한 요인으로 인해 영아의 어린 이집 이용 시간은 더 늘어나고 그 시기가 당겨질 것으로 예상 된다. 이러한 사회변화에 따라 어린 연령의 영아의 어린이집 적응에 대한 연구가 지속적으로 이루어질 필요가 있다.

여기서 적응이란 다양한 의미가 있으나, 개인의 필요와 사 회가 지니고 있는 요청이 모두 충족되고 있거나 개인과 객관 적인 환경과의 조화가 이루어진 상태를 의미한다. 또한 어떠 한 상황이나 조건에 처하더라도 그 조건에 맞게 자신의 습성 혹은 생활방식을 맞추고 조정하여 문제없이 어울리는 것이다 (Kang, 2003). 즉 영아에게 있어 어린이집 적응은 새로운 물리 적 환경에 맞춰 심리적 환경에도 순응하는 과정에서 타인과

(C)The Korean Association of Child Studies

This is an Open Access article distributed under the terms of the Creative Commons Attribution Non-Commercial License (http:// creativecommons.org/licenses/by-nc/4.0) which permits unrestricted noncommercial use, distribution, and reproduction in any medium, provided the original work is properly cited. 
조화로운 관계를 맺고 유지하는 내현적이며 외현적 행동인 것 (S. J. Seo, 2009)으로 전자는 정서적인 부분과 후자는 행동적인 부분으로 나타난다.

어린이집은 생애 최초의 사회생활 기관으로 타인과의 사 회관계 속에서 새로운 생활을 하는 것은 영유아들에게 커다 란 도전이다(K.-H. Lee, 2018). 특히 주요 애착 대상에서 분리 되어 가정에 비해 비교적 개별적인 보살핌이 부족한 어린이 집에서의 적응은 영아에게 스트레스가 될 수 있다(Jovanovic, 2011). 어린이집 적응의 스트레스를 분석하기 위해, 어린이집 에 재원 중인 영아와 유아의 코티졸 수준을 비교한 결과, 유아 에 비해 36개월 미만의 영아의 코티졸 수준이 상대적으로 높 게 나타났다(Vermeer \& van IJzendoorn, 2006). 이는 유아에 비 해 영아가 어린이 집에 적응하는 데에 상대적으로 높은 스트 레스를 받고 있음을 나타내는 것이다. 그리고 우리나라의 경 우에도, 영아의 어린이집 퇴소 사유 역시 어린이집 부적응 문 제가 $31 \%$ 로 높게 나타났다(Choi, 1994). 즉 영아의 경우, 유아 에 비해 높은 스트레스와 적응의 문제를 보일 수 있음을 예측 할 수 있다. 이와 같이 어린이집 적응하지 못하는 부적응의 문 제는 단순히 한 번의 경험으로 끝나지 않고 이후 적응에도 지 속적으로 영향을 미칠 수 있다(Ladd \& Troop-Gordon, 2003; N. Shin \& Yun, 2016). 이러한 영아의 어린이집에 대한 부적응 경 험은 이후 다른 교육기관 및 학교생활에서도 영향을 미칠 수 있다(Ladd \& Price, 1987; J. S. Song, 2004; Yang \& Moon, 2010). 따라서 영아의 초기 교육기관에 대한 성공적인적응은 향후 학교생활에서의 학문적·사회적 성취에도 결정적인 영향을 끼 치기 때문에(Dockett \& Perry, 2003) 생애 첫 단체생활로서 영 아의 어린이집 적응을 살펴보는 것은 중요하다고 할 수 있다.

그동안 영아의 어린이집 적응과 관련하여, 선행연구에서는 개인 내·외 변인으로 나누어 제시하고 있다(A. R. Song, Song, $\&$ Lee, 2015). 어린이집 적응 관련 개인 내 변인으로는 영아의 기질과 놀이 특성과 관련된 최근 연구(S. E. Seo \& Park, 2020) 와 더불어 성별과 연령(M. Lee \& Jeon, 2020; Lim \& Choi, 2003)이 제시되었다. 또한 어린이집 적응 관련 개인 외 변인으 로는 교사의 민감성(McCartney, Scarr, Phillips, \& Grajek, 1985), 어머니의 애착안정(Ahnert, Gunnar, Lamb, \& Barthel, 2004), 그 리고 보육환경의 질(Hyun \& Tae, 2000)이 제시되었다. 아울러 어머니와 영아의 관계 그리고 교사와 영아와의 관계 변인 연 구(J. H. Park \& Rha, 2017)와 개인변인 기질, 연령, 및 성별 및 또래유능성과 교사와의 관계를 함께 제시한 연구(S. L. Kim, 2012)도 있다. 특히 영아 취원율 증가와 사회적 변인에 맞물려 영아교육과 보육에서는 개인 외 변인에 해당하는 교사 역할이
부각될 필요가 있다. 영아의 어린이집 적응 관련으로 외적변 인인 교사 역할에 주목하는 데에는 영유아의 주양육자 역할이 전적으로 부모에게 주어져있던 과거와는 달리, 사회적 변화와 맞물려 교사와 부모가 그 역할을 나누게 된 데에 있다. 특히 연 령이 낮을수록 교사에게 의존하는 경향이 크므로 다른 연령 에 비하여 영아에게는 교사의 영향력이 매우 크다고 할 수 있 다(Yang \& Moon, 2010). 어린이집에서 교사는 가정에서의 어 머니 역할을 대행하는 또 다른 양육자이며 기관에서 영아들 이 환경을 적극적으로 탐색하게 하는 안전기지의 역할을 한다 (DeMuller, Denham, Schmidt, \& Mitchell, 2000).

또한 영아의 어린이집 적응에서 교사 변인의 중요성은 보 육의 질에 영향을 미치는 과정적인 측면으로 영아와 교사와 의 관계를 더 우선적으로 고려(Howes, Matheson, \& Hamilton, 1994)하는데, 이는 교사의 행동이나 유아의 경험, 발달적으로 적합한 활동의 준비, 애정적이고 민감한 보육 등으로 전문가 의 해석과 판단이 필요하며 규제하기 어려운 변인(Jun \& Lee, 2002)이기 때문이다.

따라서 영아의 어린이집 적응에서 교사 요인이 고려될 수 있으며, 특히 영아와 영아 담당교사와의 관계가 강조되는 교 사의 민감한 역할이 중요하다(Downer, Sabol, \& Hamre, 2010; You \& Hwang, 2015). 영아에 대한 교사의 민감한 반응을 기저 로 한 상호작용은 영아의 행동에 중요한 영향을 미치며(Kontos $\&$ Wilcox-Herzog, 1997), 이는 교사의 역할이 영아에게 중요함 을 제시하는 것이다(Downer et al., 2010). 영아의 어린이집 적응 에 영향을 미치는 개인 외적 변인 중 교사 변인은 시간이 흐름 에 따라 점차 강조되는 추세이다(You \& Hwang, 2015).

교사 역할에 대한 관심의 증가와 함께 교사 대상의 다양한 연구가 진행되었는데, 교사효능감의 영향력을 확인한 연구 (Goddard, Tschannen-Moran, \& Hoy, 2001; Yun \& Lee, 2018), 교사의 민감성과 영아 어린이집 적응의 관계를 살펴본 연구 (Gerber, Whitebook, \& Weinstein, 2007) 등이 지속적으로 이루 어졌다. 본 연구에서 다루어지고 있는 교사변인 중 민감성은 영아 어린이집 적응에 중요한 변인이며, 교사가 영아의 요구 에 민감하게 반응할수록 영아가 어린이집에 보다 쉽게 적응한 것으로 나타났다(Gerber, Whitebook, \& Weinstein, 2007; Yun \& Lee, 2018).

영아의 어린이집 적응에는 교사의 역할이 중요한 가운떼, 영아들은 어린이집에서 기본적인 일상생활과 대부분의 놀이 활동을 통해 어린이집에서의 하루일과에 적응해 나간다. 이러 한 영아의 놀이 활동은 발달을 돕는 매개로서의 역할도 있으 나, 영아들의 삶의 부분으로 차지하는 것이라는 교사의 놀이 
에 대한 신념(J.-E. Seo \& Lee, 2014)과 인식과 기대 여부에 따 라 교사들의 놀이 지도 역량이 달라진다(Ahn, 2011). 즉 교사 자신의 놀이에 대한 판단 능력, 교사 자신의 놀이 교수에 대해 영아들이 받을 영향에 대한 기대하는 것이 놀이 교수효능감 이다(Sung \& Kim, 2018). 이러한 놀이교수효능감은 Bandura 의 자아효능감을 토대로 해 놀이 개념을 연계한 것으로, 영아 들의 놀이에 교사의 개입하고 참여하는 자신의 행동이 영아 의 놀이에 영향을 줄 것이라 믿는 신념을 측정한 것이다(Ahn, 2011). 선행 연구(Ahn, 2011; J.-E. Seo \& Lee, 2014; Sung \& $\mathrm{Kim}, 2018)$ 에 의하면, 영아 놀이에 대한 교사의 확고한 신념과 놀이지도에 대한 자신감과 확신이 놀이교수효능감으로 표현 된다는 것이다.

영아 교사는 놀이에 참여, 관찰, 그리고 놀이 환경을 포함 한 보육환경을 마련하는 다양한 역할을 수행하는데 있어 자신 의 신념에 기초해 의사결정을 하고, 이는 곧 교실에서의 교사 행동으로 나타난다(E.-S. Shin, Yu, \& Park. 2004). 이러한 교사 의 행동은 영아의 교실 내 생활에 영향력이 크다고 할 수 있으 며, 교사 효능감이 높은 교사는 영아들의 수월한 적응을 돕는 것(Sung \& Kim, 2018)으로 나타났다. 기존의 연구에서는 교사 효능감이 영아의 교실 환경, 어린이집에서의 안정적인 생활 그리고 적응과 밀접한 관련이 있음(J.-E. Seo \& Lee, 2014; Yun $\&$ Lee, 2018)을 일관성 있게 보고하고 있다. 그러나 선행연구 에서 제시한 교수효능감과 놀이교수효능감은 모두 Bandura의 자아효능감을 토대한 것이라는 점과 영아들의 어린이집 일상 에서 놀이가 차지하는 비중을 고려한다면, 놀이교수효능감은 영아 교사의 민감성을 예측하는 연구가 시도될 필요가 있다.

놀이교수효능감과 영아의 어린이집 적응과 관련하여, 영 아 교사는 영아 보육에 필요한 지식을 근거로 민감하게 접근 할 필요가 있다(Ladd \& Troop-Gordon, 2003). 교수효능감은 교사개인의 심리적인 문제로 놀이교수효능감 혹은 보육교사 의 교수효능감이 자신의 교수역할과 능력 대한 기대와 믿음이 라는 면에서 교수효능감이 높은 영아교사는 영아의 행동에 대 한 성취에 대해 긍정적 기대, 자신의 업무에 대한 뚜렷한 목표 의식, 자신감과 열정을 가지고 역할을 수행하므로 보육과 영 아에 대한 책임감이 높다(Glickman \& Tamashiro, 1982). 이러 한 자신의 업무와 영아에 대한 책임감은 영아의 요구, 행동, 놀 이맥락에 대한 민감성으로 이어질 것이다. 이는 영아를 맡고 있는 교사가 영아와의 정서적 교감 그리고 영아의 요구에 대 한 해석을 정확하게 할 것을 의미한다. 특히 영아 교사의 민감 성 변인은 영아의 주요발달에 중요한 변인이며, 동시에 영아 의 어린이집 적응에 중요한 질적 변인(Gerber, Whitebook, \&
Weinstein, 2007; A. R. Song, Song, \& Lee, 2015)이다.

이러한 영아 교사의 민감성은 영아의 단순한 것에서 복잡한 것에 이르는 개인적 요구에 대한 신호 인지와 해석, 그리고 영아 의 발달 능력을 향상시키는 비계설정과 같은 적절한 반응을 포 함한 일련의 반응양식이며 상호교류의 과정이다(Ladd \& TroopGordon, 2003). 교사와 영아의 관계 및 질 높은 상호작용의 기저 에는 교사의 민감성이 핵심 요인이다(You \& Hwang, 2015).

이러한 영아 교사 민감성 관련 변인은 회복탄력성, 효능감, 전문성, 직무스트레스, 그리고 심리적 소진 등이 제안되었다 (M. Y. Kim \& Chung, 2014). 보육교사의 민감성에 대해 개인 심리적 변인인 보육신념과 보육효능감을 제시한 연구에서는 보육효능감이 높을수록 긍정적 민감성이 높았음을 보고했다 (Oh, 2011). 여기서 교수효능감은 교육과 관련하여 영유아에 게 미치는 요인들에 대한 교사의 보편적인 태도와 관련된 것 으로 학습자로부터 긍정적인 변화를 이끌어 낼 수 있는 교사 자신의 기대와 관련된 것(E.-S. Shin, Yu, \& Park, 2004)으로 영 유아교육의 맥락에서 놀이는 가장 효과적인 바람직한 학습방 법은 놀이를 통해 이루어진다(Chon \& Ohm, 2011)는 점에 주 목할 필요가 있다. 교사는 놀이활동을 통해 영유아의 발달을 지원하고 놀이 맥락에서 교수과제 수행하는데 있어 관련된 주 요 변인으로 놀이교수효능감을 제안하였다(Chung, Kim, \& $\mathrm{Kim}, 2016)$. 이러한 흐름에서 보육교사의 교수효능감과 영아 교사의 놀이교수효능감을 같은 맥락으로 이해할 수 있으며, 영아교사의 놀이교수효능감은 영아교사의 민감성에 영향을 미치는 변인이라 볼 수 있다. 특히 영아담교사의 보육효능감 과 자아탄력성 변인이 교사민감성에 미치는 영향을 분석한 연 구(Noh \& Lee, 2015)를 통해 교사효능감은 영아 교사 민감성 에 영향을 주는 변인이 될 수 있으며, 본 연구에서 제안하는 교 사의 놀이 교수효능감 역시 영아 교사의 민감성의 예측변인임 가정할 수 있다. 더불어 보육교사의 높은 효능감은 영유아의 안정적인 적응을 촉진(Yun \& Lee, 2018)을 보고했다. 영아 교 사의 놀이교수효능감 혹은 보육교사의 교수효능감과 영아의 어린이집 적응을 분석한 기존의 연구(Noh \& Lee, 2015; Yun \& Lee, 2018)에서는 이들 간의 영향관계에 초점을 두고 분석되 고 있으며, 이에 대한 구조적 관계를 분석한 연구는 찾기 어렵 다. 따라서 본 연구에서는 놀이 교수효능감이 영아의 어린이 집 적응에 영향을 미치는 경로와 구조를 분석하고자 함에 있 어 놀이교수효능감과 민감성의 관련성 연구에 힘입어 교사의 놀이 교수효능감이 높을수록 영아들의 어린이집 적응이 더욱 수월하리라고 예측하였다.

따라서 본 연구에서는 영아의 어린이집 적응에 영향을 주 
는 변인 중 놀이 교수효능감과 영아 교사의 민감성에 대해 분 석하고자 한다. 영아기는 발달 특성상 분명한 자신의 의사표 현 불가능하므로 영아의 다양한 신호를 알아내고 이에 적절히 반응하는 교사의 능력이 필요하다. 그러므로 놀이 교수효능감 이 어린이집 적응에 미치는 영향 분석과 아울러 영아 교사민 감성의 매개효과를 분석하고자 한다(Figure 1 참조). 이러한 연 구 결과는 영아의 어린이집 적응을 도울 수 있는 교육활동 및 구체적인 교사역할을 모색하고 더불어 영아 교사교육의 근거 자료로 활용될 수 있다.

\section{연구문제 1}

놀이 교수효능감, 영아 교사민감성, 그리고 어린이집 적응 간 의 관계는 어떠한가?

\section{연구문제 2}

놀이 교수효능감과 어린이집 적응의 관계에서 영아 교사민감 성의 매개효과는 어떠한가?

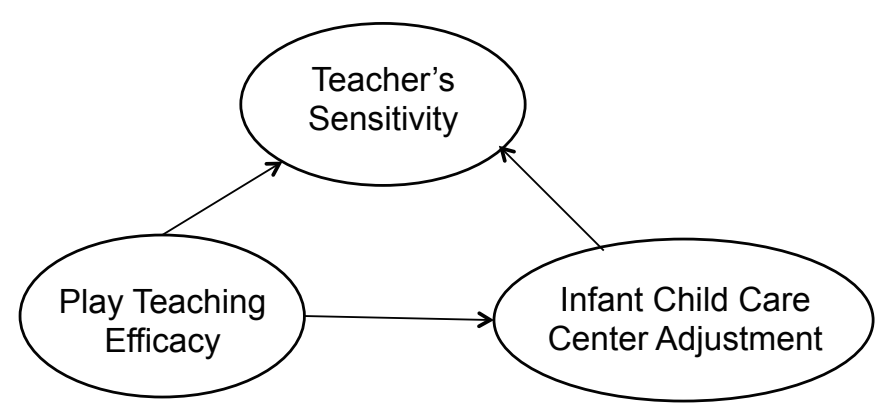

Figure 1. Hypothesized model.

\section{Methods}

\section{연구대상}

본 연구는 경기와 강원 지역의 국. 공립 어린이집을 각 지역 육 아지원센터를 통해 임의표집한 후 해당기관에 근무하고 있 는 교사 405 명과 각 교사가 담당하는 영아 1 명을 선정하여 연 구자료를 수집하였다. 교사의 영아 선정 기준은 3 월에 입소하 여 자료수집 기간에 만 2 세인 영아 중, 영아의 이름을 기준으 로 가나다순의 처음에 해당하며, 부모가 동의한 영아를 선정 하도록 했다. 교사의 평균 교육경력은 5년 9개월이었으며, 모 두 4년제 대학의 유아교육과 및 아동학과를 졸업하였다. 이들 에게 2019년 10월 1 일부터 10 월 20 일까지 총 405 부의 질문지
를 배부하여 그 중에서 402부를 회수하였고, 이 중 응답이 누 락되었거나 중복 표기된 불완전한 자료 3 부를 제외하고 나머 지 399부를 최종 연구 자료로 활용하였다. 대상 영아는 만 2 세 영아 399 명중 남아가 200 명 여아가 199 명이었다.

\section{연구도구}

$$
\text { 놀이 교수효능감 }
$$

교사의 놀이 교수효능감을 측정하기 위해 개발한 도구(E.-S. Shin, Yu, \& Park, 2004)를 사용했다. 이는 영아 담당교사의 놀 이교수 효능 신념(12문항)과 놀이교수 결과 기대(9문항)로 총 21 문항으로 구성되었다(E.-S. Shin, Yu, \& Park, 2004). 본 도구 는 5점 평정척도로 점수가 높을수록 교사의 놀이 교수효능감 이 높음을 의미한다. 본 연구에서 나타난 놀이 교수효능감 척 도의 신뢰도 Cronbach's $\alpha$ 는 .89로 나타났다.

\section{교사민감성}

교사의 민감성을 측정하기 위해 개발한 도구(Min \& Lee, 2015)를 사용하였다. 영아 교사의 민감성 측정도구는 적절성, 정확성, 즉시성, 일관성, 그리고 융통성의 5 개 영역의 32 문항 으로 구성되었다. 교사민감성에서의 적절성은 행동이 일어난 상황과 상태에 따라 적절한 반응을 해주는 것을 의미하며(9문 항), 정확성은 영유아로부터 지각한 내용을 왜곡되지 않게 해 석하는 것을 의미하며(6문항), 즉시성은 영유아의 신호를 즉 시 알아채고 해결해주는 것을 말하며(8문항), 일관성은 영유 아의 신호에 같은 반응을 보여 주는 것(4문항), 융통성은 영아 들 개개인 또는 영아가 속한 반의 형편에 맞도록 수정하고 보 완하는 것(5문항)이다(Min \& Lee, 2015). 각 문항은 4점 평정 척도이며, 점수가 높을수록 민감성이 높음을 의미한다. 본 연 구에서 나타난 영아 교사 민감성 척도의 신뢰도 Cronbach's $\alpha$ 는 적절성 .93 , 정확성 .90 , 즉시성 .91 , 일관성 .89 , 그리고 융통 성 .90 이며, 전체는 .90 이었다.

\section{어린이집 적응}

영아의 어린이집 적응 정도를 알아보기 위해 Jewsuwan, Luster 와 Kostelnik (1993)이 개발하고 Oh (2001)가 번역한 도구를 영 아에게 적합하게 수정, 보완한 도구(Kim \& Kwon, 2005)를 사 용하였다. 영아의 어린이집 적응 측정은 교사가 평정하였으 
Table 1

Correlation Among Variables

\begin{tabular}{lccc}
\hline & Play-teaching efficacy & Infant teachers'sensitivity & Child care center adjustment \\
\hline Play-teaching efficacy & - & & \\
Infant teachers' sensitivity & $.58^{* *}$ & - & $42^{* *}$ \\
Child care center adjustment & $.45^{* *}$ & - \\
\hline
\end{tabular}

${ }^{* *} p<.01$.

Table 2

Goodness of Fit of the Meditation Model

\begin{tabular}{ccccc}
\hline$\chi^{2}$ & $d f$ & TLI & CFI & RMSEA \\
\hline $110.844^{* * *}$ & 39 & .951 & .969 & .068 \\
\hline$* * * p<.001$. & & & &
\end{tabular}

며, 친사회적 행동(4문항), 긍정적 감정(7문항), 또래관계(6문 항), 자아강도(4문항), 일과에 대한 적응(9문항)의 5 개 영역의 총 30문항으로 구성되었다. 4점 평정척도로 점수가 높을수록 적응을 잘하고 있음을 나타낸다. 본 연구에서 나타난 영아의 어린이집 적응 척도의 신뢰도 Cronbach's $\alpha$ 는 .91이었다.

\section{연구절차}

본 연구를 수행하기 전 영아 담당 보육교사 5 명을 대상으로 예 비조사를 실시하였다. 이러한 과정에서 5 명의 교사들에게 질 문지에 소요되는 시간 측정과 내용이해에 대한 검토를 받았 다. 그리고 완성된 질문지는 유아교육 전공 교수 2 인에게 내용 타당도를 검증받아 측정도구의 사용과 연구 진행에 무리가 없 을 것으로 판단되어 본 조사와 연구를 실시하였다.

본 조사를 위한 연구대상의 선정과정은 경기육아종합지원 센터와 강원도 내 각 지역 육아지원센터를 통해 167 개의 기관 을 임의표집하였다. 지역 센터를 통해 어린이집의 연락처 수 집한 후 유선으로 연구 참여 의사를 밝힌 어린이집 159 개 기 관을 방문하여 연구대상 영아의 담임교사를 만나 연구에 대한 설명과 별도의 공간에서 설문을 실시하였다.

\section{자료분석}

본 연구는 SPSS 21.0 (IBM Co., Armonk, NY)과 Amos 24.0 (IBM Co., Armonk, NY)프로그램을 통해 분석되었다. 각 변 인들 간의 관계 분석을 위해 SPSS 21.0 프로그램과 Amos 24.0 프로그램을 사용하였다. 연구모형에 대한 구조 분석과 각 변 인 간 경로의 확인은 구조방정식 모형을 이용했다. 이후 경로 계수를 통한 놀이 교수효능감, 영아교사의 민감성, 및 영아의
적응 간의 직.간접 효과 검증과 부스트래핑 방법을 통한 매개 효과의 통계적 유의성을 확인하였으며, 부스트래핑 표본은 5,000회로 설정하였다.

\section{Results}

\section{놀이 교수효능감, 영아 교사민감성과 어린이 집의 적응 간의 관계}

연구모형 분석에 앞서, 놀이 교수효능감, 영아 교사민감성 그 리고 영아의 어린이집 적응의 간의 상관관계를 분석했다. 놀 이 교수효능감, 영아의 어린이집 적응, 그리고 교사민감성 간 에는 유의미한 정적 상관관계가 나타났다. 놀이 교수효능감과 영아의 어린이집 적응 $(r=.45, p<.01)$, 놀이 교수효능감과 교 사민감성 $(r=.58, p<.01)$, 교사민감성과 영아의 어린이집 적 응 $(r=.42, p<.01)$ 은 유의미한 정적 상관관계를 보였다. 놀이 교수효능감, 교사민감성, 그리고 영아의 어린이집 적응 간에 는 유의미한 정적 상관관계가 있었다(Table 1 참조).

\section{놀이 교수효능감과 적응과의 관계에서 교사 민감성의 매개효과}

\section{연구모형}

놀이 교수효능감과 적응과의 관계에서 교사민감성의 매개효 과를 분석하기 위한 연구모형의 적합도를 확인한 결과, $\chi^{2}$ 는 $110.844(d f=39)$, TLI는 .951, CFI는 .969, RMSEA는 .068인 것 으로 나타나 양호한 수준인 것으로 나타났다(Table 2 참조). 
Table 3

Parameter Estimates of Model

\begin{tabular}{|c|c|c|c|c|c|}
\hline Paths & Estimate & Standardized-estimate & $S E$ & $C R$ & $p$ Label \\
\hline Play-teaching efficacy $\rightarrow$ Infant teachers' sensitivity & .25 & .65 & .01 & 15.91 & 0.00 \\
\hline Play-teaching efficacy $\rightarrow$ Child care center adjustment & .85 & .26 & .19 & 4.34 & 0.00 \\
\hline
\end{tabular}

Table 4

Confirmatory Bootstrapping Analysis for the Mediating Effects of Infant Teachers' Sensitivity

\begin{tabular}{|c|c|c|c|c|c|c|}
\hline \multirow[b]{2}{*}{ Path of observed variables } & \multirow[b]{2}{*}{ Estimate } & \multirow[b]{2}{*}{$\begin{array}{l}\text { Standardized } \\
\text {-estimate }\end{array}$} & \multirow[b]{2}{*}{$S E$} & \multicolumn{2}{|c|}{$95 \% \mathrm{CI}$} & \multirow[b]{2}{*}{ p Label } \\
\hline & & & & $\begin{array}{l}\text { Boot } \\
\text { LLCI }\end{array}$ & $\begin{array}{l}\text { Boot } \\
\text { ULCI }\end{array}$ & \\
\hline
\end{tabular}

Table 5

Direct, Indirect, and Total Effect Among Variables of the Model

\begin{tabular}{lccc}
\hline \multicolumn{1}{c}{ Variables } & Direct effect & Indirect effect & Total effect \\
\hline Play-teaching efficacy $\rightarrow$ Infant teachers' sensitivity & $.65^{* * *}$ & .00 & $.65^{* * *}$ \\
Infant teachers' sensitivity $\rightarrow$ Child care center adjustment & $.28^{* * *}$ & .00 & $.28^{* * *}$ \\
Play-teaching efficacy $\rightarrow$ Child care center adjustment & $.26^{* * *}$ & $.18^{* * *}$ & $.44^{* * *}$ \\
\hline
\end{tabular}

${ }^{* * *} p<.001$.

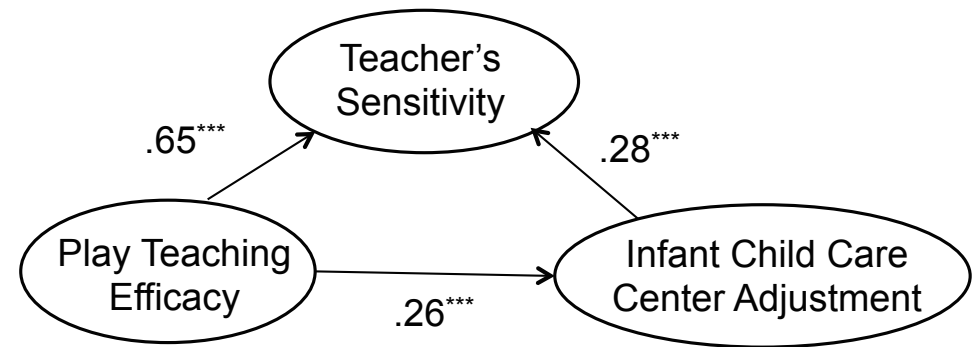

Figure 2. The effects of play-teaching efficacy and teacher's sensitivity on infants' child care center adjustment.

${ }^{* * *} p<.001$.

연구모형에 대한 구조방정식 모델의 추정치 결과를 제시 하였다(Table 3 참조). 놀이 교수효능감이 영아 교사민감성에 정적인 영향을 주었고, 놀이 교수효능감이 적응 $(\beta=.26, p<$ .001)에 정적인 영향을 주었다. 그리고 교사민감성은 적응 $(\beta=$ $.28, p<.001)$ 에 영향을 주는 것으로 나타났다.

매개효과 검증

본 연구모형에서는 교사의 놀이 교수효능감과 영아의 어린이 집 적응의 관계에서 교사민감성의 매개효과가 있는지 경로의 간접효과를 확인하기 위해 부스트래핑 방법을 통해 검증하였 다(Table 4 참조). 부스트래핑을 통해 매개효과를 검증한 결과,
$95 \%$ 신뢰구간에서 놀이 교수효능감 $\rightarrow$ 교사민감성 $\rightarrow$ 적응 의 간접효과 크기는 .08 .26이었다. 효과의 범위가 0을 포함 하지 않으므로 간접효과는 유의하다고 판단된다. 놀이 교수효 능감이 적응에 미치는 영향에서 교사의 민감성 매개효과가 존 재함을 확인할 수 있었다 $(\beta=.18, p<.001)$.

놀이 교수효능감와 교사민감성이 어린이집 적응에 미치는 직접효과, 간접효과 그리고 총효과를 살펴보았다(Table 5 참 조). 따라서 놀이 교수효능감은 교사민감성에 직접효과가 있 고 정적관계이므로, 교사의 놀이 교수효능감이 높을수록 영아 에 교사의 민감성이 높다. 그리고 교사의 민감성은 영아의 어 린이집 적응에 직접효과가 있고 정적관계이므로, 교사의 민감 성이 높을수록 영아는 어린이집 적응을 더욱 잘 할 수 있다. 또 
한 교사의 놀이 교수효능감은 교사의 민감성을 매개로 하여 영아의 어린이집 적응에 간접적인 영향을 미치는 것으로 나타 났다 $(\beta=.18, p<.01)$. Figure 2 에 놀이 교수효능감과 영아의 어 린이집 적응의 관계에서 교사 민감성의 매개효과에 대한 최종 모형을 제시했다. 이를 통해 영아의 어린이집 적응을 돕기 위 해서는 교사의 놀이 교수효능감의 고양과 더불어 교사의 민감 성을 높일 수 방안을 마련하는 것이 중요함을 확인했다.

\section{Discussion}

본 연구에서는 놀이 교수효능감, 어린이집 적응 및 영아 교사 의 민감성 간의 관계를 확인하고 놀이 교수효능감과 어린이집 적응 간의 관계에서 영아 교사의 민감성이 매개효과를 탐색하 고자 했다. 본 연구에서의 결과를 선행연구에 비춰 논의하면 다음과 같다.

첫째, 교수효능감, 적응, 그리고 교사민감성 간에는 유의미 한 정적 상관관계가 있었다. 즉 놀이 교수 효능감과 교사 민감 성 그리고 놀이 교수효능감과 적응 간의 관계는 비교적 높은 정도의 유의미한 정적 상관관계를 나타냈다. 그리고 교사 민 감성과 적응은 유의미한 정적 상관관계를 나타냈다.

교수효능감은 학습자에게 긍정적인 변화를 가져오게 할 수 있다는 자신의 능력에 대한 긍정적 평가이다(Goddard, Tschannen-Moran, \& Hoy, 2001). 여기서 '학습자에 대한 긍정 적인 변화'는 일반적인 의미에서 교육이 무엇인지와 관련된 것으로, 교수효능감은 어느 시기 어떤 교육을 담당하든 교사 의 가장 근본적인 자질에 해당한다. 특히 놀이 교수효능감에 서의 '놀이'는 영유아 및 아동의 기관적응의 중요한 예측변인 이다(S. J. Park \& Lee, 2019). 더불어 놀이 교수효능감과 영아 교사의 놀이신념, 영아와의 상호작용을 분석한 선행연구(J.-E. Seo \& Lee, 2014)에 비춰볼 때, 놀이 교수효능감은 영아의 어 린이집 적응과 밀접한 관련이 있다고 볼 수 있다. 이러한 선행 연구들 간의 상호관련성은 본 연구의 놀이 교수효능감, 적응 그리고 교사민감성 간에 관련이 있다는 결과를 뒷받침하는 유 사한 맥락이다.

본 연구에서 제시된 결과를 보면, 교사민감성과 영아의 어 린이집 적응은 밀접한 관련을 나타냈다. 특히 영아 교사민감 성과 영아의 어린이집 적응의 관계에서 교사는 영아가 보내는 언어적 신호 뿐 아니라, 비언어적 신호에 대해서도 표정이나 몸짓 등을 보고도 즉시 알아채고 해결해줌으로써 교사와 영아 의 반응을 하나로 서로 연결시킬 수 있을 만큼 충분히 즉각적
인 행동을 보여주는 교사의 반응이다(Min \& Lee, 2015). 교사 는 영아에 대해 예리한 관찰을 통해 그들을 이해하고 즉각적 으로 반응하는 것이 중요하며, 이를 통해 교사와 영아 간의 안 정된 애착을 형성한다. 그리고 민감한 교사가 영아의 적응행 동을 높이며, 이러한 교사의 영향이 영아의 어린이집 적응에 중요한 역할을 한다(N. Shin \& Yun, 2016). 따라서 놀이 교수 효능감, 어린이집 적응, 그리고 교사의 민감성은 밀접한 관련 성을 나타낸 본 연구결과는 선행연구(Min \& Lee, 2015)와 유 사한 맥락이다. 이러한 연구변인들은 어린이집에서의 질적 수 준을 높일 수 있는 주요한 변인이므로 추후에도 각 하위변인 에 대한 심도 깊은 연구가 필요한 영역이다.

둘째, 놀이 교수효능감과 영아의 어린이집 적응 간의 관계 에서 교사의 민감성의 매개효과를 분석한 결과, 영아 교사민 감성은 놀이 교수효능감과 영아의 어린이집 적응 관계에서 매 개변인의 역할을 하는 것으로 나타났다.

우선 본 연구의 주요 분석 결과 결과로 영아 교사민감성은 놀이 교수효능감과 영아의 어린이집 적응의 관계를 부분 매개 하는 것으로 나타났다. 이는 영아들이 어린이집에 잘 적응하 기 위해서는 교사의 놀이 교수효능감이 높고 동시에 교사의 민감성이 동반되어야 함을 의미한다. 놀이 교수효능감이 높은 교사는 영아와 놀이 상황에서 긍정적인 정서를 더 많이 표현 한다(Yun \& Lee, 2018). 긍정적인 정서를 표현하는 가운데 영 아의 관찰하고 민감하게 상호작용할 수 있는 기회가 많아지는 데, 놀이 교수효능감을 포함한 교수효능감이 높은 교사는 영 아의 행동을 더욱 민감하게 관찰하고 반응하는 것으로 나타났 다(Noh \& Lee, 2015). 영아 담당 교사는 영아들의 하루일과에 서 즐거운 놀이과정에서 더욱 민감한 관찰에 근거한 적합한 상호작용을 통해 놀이를 더욱 풍부하게 하고 이는 궁극적으로 영아의 어린이집 적응을 돕는 것으로 볼 수 있다.

좀 더 구체적인 연구 결과를 보면, 놀이 교수효능감은 영아 교사의 민감성에 유의한 영향을 미치는 것으로 나타났다. 이 는 놀이에 대한 긍정적인 믿음을 가지고 영아들의 놀이를 관 찰하고, 개입하고 참여할 수 있는가를 스스로 인식하는 교사 전문성으로, 놀이 교수효능감이 영아의 어린이집 적응을 돕 는다는 것을 확인한 것이다. 특히 영아에게 있어 놀이 활동은 삶 그 자체이다. 이러한 놀이 활동이 활발하고 풍부하게 이루 어지기 위해서는 교사의 역할이 중요하다. 교사의 놀이 지원 에 대한 자신감과 확신은 놀이 교수효능감으로 나타난다(J.E. Seo \& Lee, 2014). 놀이 교수효능감이 높은 교사는 학습자 에게 많은 기회를 주고 반응하고, 학습자를 긍정적인 방향으 로 지도하고(Gibson \& Dembo, 1984), 영아의 놀이 특성, 놀이 
맥락에 맞는 적절한 상호작용을 제공한다(Bigelow, Maclean, $\&$ Proctor, 2004). 이는 교사가 영아의 개인차에 대해 민감하게 반응하고 긍정적인 언어적 상호작용과 표정 등 기관에서의 주 양육자로의 역할을 잘 수행하고 있음을 나타내는 것이다.

다음으로 교사의 민감성은 영아의 어린이집 적응에 정적인 영향을 미치는 것으로 나타났다. 영아 교사민감성은 단순한 것에서 복잡한 것에 이르기까지 영아의 개인적 요구를 파악하 는 능력, 긍정적인 상호작용, 발달과 학습의 비계설정까지 보 육의 질적 수준을 가늠하는 주요 요인이다(Gerber, Whitebook, $\&$ Weinstein, 2007).

어린이집에 재원 중인 영아들은 가정에서의 어머니만큼이 나 혹은 그 이상의 긴 시간을 교사와 보내게 된다. 이는 교사와 의 애착형성이 중요함을 의미하는데, 행동조절에 어려움을 보 이는 영아에게 교사는 민감한 상호작용과 양육을 통해 안정된 애착을 형성한다(Howes \& Ritchie, 1998). 그리고 교사의 민감 한 상호작용을 통한 영아와 교사와의 돈독한 관계는 어린이집 적응과 관련성이 있다(Gerber, Whitebook, \& Weinstein, 2007). 또한 교사와 안정애착을 형성한 영아가 또래관계도 더 원활하 다는 보고(Howes, Matheson, \& Hamilton, 1994)도 있다. 따라 서 영아의 어린이집 적응과 이를 위한 정서적 지원을 위해서 는 교사의 민감성이 중요하며, 이에 대한 영아 교사교육이 더 욱 활발하게 이루어질 필요가 있다.

한편 놀이 교수효능감은 영아의 어린이집 적응에 직.간접 적인 영향을 미치는 것으로 나타났다. 영아 교사가 영아의 놀 이활동에 효과적으로 개입하고 풍부화 할 수 있다는 교수효 능감에 대한 신념과 효과적 놀이교수가 영아의 놀이에 영향 을 줄 것이라는 교수 결과에 기대를 포함하는 놀이 교수효능 감은 보육교사의 전문성과 관련이 있다(E.-S. Shin, Yu, \& Park, 2004). 따라서 놀이 교수효능감이 높은 교사와의 상호작용을 통한 풍부한 놀이는 영아의 어린이집 적응을 돕는 중요한 교 육활동 임을 확인하였다.

본 연구는 놀이 교수효능감, 교사의 민감성, 그리고 영아의 어린이집 적응 간의 관계 및 교사민감성의 매개효과를 밝히 기는 했으나, 다음의 몇 가지에서 한계가 있다. 우선, 본 연구 에서는 교사가 담당하고 있는 영아 1 인을 선정하여 어린이집 적응 측정하였다는 데에 있다. 연구대상인 교사가 연구대상 인 영아를 선정한 부분은 연구결과에 영향을 미칠 수 있어 연 구결과를 일반화하여 해석하는 데에 한계가 있다. 따라서 교 사의 측정 결과뿐 아니라 보다 다양한 자료를 활용할 필요가 있다. 둘째, 어린이집 적응을 측정하는 도구로 교사가 평정하 는 평이한 도구를 사용했다는 점에서 연구의 한계가 있다. 이
후 후속연구에서는 적응을 평가하기 위해 다양한 관점에 영아 를 바라보는 노력도 필요할 것이다. 이러한 맥락에서, 최근 영 아의 어린이집 적응을 객관적으로 이해할 수 있는 도구로 타 액 코티졸 분석법의 주목(K.-H. Lee, 2018)과 교사와 좋은 관계 를 맺는 것이 코티졸의 하강하는 코티졸의 일일 변화 패턴과 관련이 있음(Lisonbee, Mize, Payne, \& Granger, 2008)을 통해 코티졸의 변화를 어린이집 적응을 이해하기 위한 도구로 제안 될 수 있다. 영아가 안정적인 또래관계, 교사와 영아관계를 맺 고, 어린이집 적응에 대한 적절한 지도를 받기 위해서는 보육 교사의 전문성을 높이는 것이 중요하다는 정책제언(J. Lee \& Lee, 2020)이 있었다. 결국 어린이집에서의 보육교사의 전문 성 발휘는 여러 영역에서 나타날 수 있으나, 놀이 교수효능감 을 통해서 그 능력이 더욱 빛날 수 있음을 유념할 필요가 있다. 셋째, 놀이 교수효능감, 교사민감성 그리고 영아의 어린이집 적응과 관련하여 전반적인 종단연구 또한 진행될 필요가 있을 것이다.

그럼에도 불구하고 본 연구에서는 영아의 삶에 중요한 놀 이와 교사의 전문성을 드러낼 수 있는 교수효능감의 맥락에서 놀이 교수효능감을 제안하여, 영아 교사의 민감성, 어린이집 적응 간의 관련성을 밝히고, 영아 교사의 민감성의 매개효과 를 제시하였다는 점에서 연구의 의의가 있다. 본 연구를 통해 영아의 적응을 이해할 수 있는 근거와 영아 교사교육 내용 개 발 자료로 활용될 수 있을 것이다.

\section{Notes}

This article was presented as a poster at the 2020 Annual Spring Conference of the Korean Association of Child Studies.

\section{Conflict of Interest}

No potential conflict of interest relevant to this article was reported.

\section{References}

\section{In English}

Ahnert, L., Gunnar, M. R., Lamb, M. E., \& Barthel, M. (2004). 
Transition to child care: Associations with infant-mother attachment, negative emotion, and cortisol elevations. Child Development, 75(3), 639-650. doi:10.1111/j.14678624.2004.00698.x

Bigelow, A. E., MacLean, K., \& Proctor, J. (2004). The role of joint attention in the development of infants' play with objects. Developmental Science, 7(5), 518-526. doi:10.1111/j.14677687.2004.00375.x

DeMuller, E. K., Denham, S., Schmidt, M., \& Mitchell, J. (2000). Q-sort assesment of attachment security during the preschool years: Links from home to school. Developmental Psychology, 36(2), 274-282. doi:10.1037/0012-1649.36.2.274

Dockett, S., \& Perry, B. (2003). The transition to school: What's important? Educational Leadership, 60(7), 30-33.

Downer, J., Sabol, T. J., \& Hamre, B. (2010). Teacher-child interactions in the classroom: Toward a theory of within-and cross-domain links to children's developmental outcomes. Early Education and Development, 21(5), 699-723. doi:10.10 80/10409289.2010.497453

Gerber, E. B., Whitebook, M., \& Weinstein, R. S. (2007). At the heart of child care: Predictors of teacher sensitivity in center-based child care. Early Childhood Research Quarterly, 22(3), 327-346. doi:10.1016/j.ecresq.2006.12.003

Gibson, S., \& Dembo, M. H. (1984). Teacher efficacy: A construct validation. Journal of Educational Psychology, 76(4), 569582. doi:10.1037/0022-0663.76.4.569

Glickman, C. D., \& Tamashiro, R. T. (1982). A comparison of first-year, fifth-year, and former teachers on efficacy, ego development and problem solving. Psychology in the Schools, 19(4), 558-562. doi:10.1002/1520-6807(198210) 19:4<558::AID-PITS2310190426>3.0.CO;2-F

Goddard, R. D., Tschannen-Moran, M., \& Hoy, W. K. (2001). A multilevel examination of the distribution and effects of teacher trust in students and parents in urban elementary schools. The Elementary School Journal, 102(1), 3-17. doi:10.1086/499690

Howes, C., Matheson, C. C., \& Hamilton, C. E. (1994). Maternal, teacher, and child care history correlates of children's relationships with peers. Child Development, 65(1), 264-273. doi:10.1111/j.1467-8624.1994.tb00749.x

Howes, C., \& Ritchie, S. (1998). Changes in child-teacher relationship in therapeutic preschool program. Early Educational Development, 9(4), 411-422. doi:10.1207/s15566935eed0904_6

Jewsuwan, R., Luster, T., \& Kostelnik, M. (1993). The relation between parents' perceptions of temperament and children's adjustment to preschool. Early Childhood Research Quarterly, 8(1), 33-51. doi:10.1016/S0885-2006(05)80097-3

Jovanovic, J. (2011). Saying goodbye: An investigation into parentinfant separation behaviours on arrival in childcare. Child Care in Practice, 17(3), 247-269. doi:10.1080/13575279.2 011.571237
Kontos, S., \& Wilcox-Herzog, A. (1997). Teachers' interaction with children: Why are they so important? Retrieved from ERIC database. (EJ538100)

Ladd, G. W., \& Price, J. M. (1987). Predicting children's social and school adjustment following the transition from preschool to kindergarten. Child development, 58(5), 1168-1189. doi: $10.2307 / 1130613$

Ladd, G. W., \& Troop-Gordon, W. (2003). The role of chronic peer difficulties in the development of children's psychological adjustment problems. Child Development, 74(5), 1344-1367. doi:10.1111/1467-8624.00611

Lisonbee, J. A., Mize, J., Payne, A. L., \& Granger, D. A. (2008). Children's cortisol and the quality of teacher-child relationships in child care. Child Development, 79(6), 18181832. doi:10.1111/j.1467-8624.2008.01228.x

McCartney, K., Scarr, S., Phillips, D., \& Grajek, S. (1985). Day care as intervention: Comparisons of varying quality programs. Journal of Applied Developmental Psychology, 6(23), 247-260. doi:10.1016/0193-3973(85)90061-9

Vermeer, H. J., \& van IJzendoorn, M. H. (2006). Children's elevated cortisol levels at daycare: A review and metaanalysis. Early Childhood Research Quarterly, 21(3), 390401. doi:10.1016/j.ecresq.2006.07.004

\section{In Korean}

Ahn, H. J. (2011). A study on the relationship between daycare teachers' efficacy belief on play and acceptability of improving social skills strategies for children with disabilities. Korean Journal of Human Ecology, 20(4), 777-787.

Choi, H. J. (1994). A practical study on opening and implementing a child care center: Focusing on Sae-Am child care center. The Korea Association of Child Care and Education, 1, 62-84.

Chon, H.-H., \& Ohm, J.-A. (2011). The expert teachers' experiences in applying plays to the kindergarten curriculum and their ways to resolve difficulties. Early Childhood Education Research \& Review, 15(5), 305-334.

Chung, M. R., Kim, S. K., \& Kim, M. J. (2016). The sequential mediation effects of efficacy belief about play and professional recognition between kindergarten teacher's emotional intelligence and teacher-child interaction. Journal of Korean Child Care and Education, 12(3), 137-157. doi:10.14698/ jkcce.2016.12.03.137

Hyun, O, K., \& Tae, J. (2000). Quality of child care environment and toddler's adjustment in child care centers-based on child care centers in Inchon. Journal of the Korean Home Economics Association, 38(3), 25-42.

Jun, C.-A., \& Lee, M.-S. (2002). The social competence of children with reference to day care center's structural, process variables and demographic variables. Journal of 
Korean Home Management Association, 20(1), 115-124.

Kim, J., \& Kwon, M. (2005). A study of the relationships among infant's attachment, temperament and the early adjustment to day-care center. The Korean Journal of Human Development, 12(4), 177-189.

Kang, J. W. (2003). The process of enhancing social relationship through theraplay with children who have maladjusted behavior: From exploration to growth (Doctoral dissertation). Retrieved from http://www.riss.kr/link?id=T9741990

Kim, M, Y., \& Chung, O.-B. (2014). The sensitivity of teachers in infant day-care: a study focused on environmental variables and individual variables. The Korean Journal of Human Development, 21(2), 75-96.

Kim, S. L. (2012). A Study of young children's adjustment to childcare centers: Focusing on the individual variables, peer competence, and child-teacher relationship. Journal of Korean Child Care and Education, 18(4), 207-230.

Lee, J., \& Lee, K. (2020). Children's diurnal change in salivary cortisol in relation to temperament, peer relationship and teacher-child relationship: Differences according to childcare duration. Korean Journal of Child Studies, 41(1), 75-87. doi:10.5723/kjcs.2020.41.1.75

Lee, K.-H. (2018). A longitudinal study among early childhood variables influencing school adjustment. The Journal of Korea Open Association for Early Childhood Education, 23(6), 399-425. doi:10.20437/KOAECE23-6-17

Lee, M., \& Jeon, I. (2020). The effects of toddler's gender, age, social-emotional development and interaction with their teacher on adaptation to childcare center. Journal of Future Early Childhood Education, 27(2), 193-213. doi:10.22155/ JFECE.27.2.193.213

Lim, M. J., \& Choi, K. S. (2003). A study of children's adjustment to child-care centers based upon gender age, temperament and home environment. Journal of Early Childhood Education, 23(1), 189-207.

Min, K. M., \& Lee, J. H. (2015). The development of the infant teacher's sensitivity scale. Journal of Children's Literature and Education, 16(1), 229-249.

Noh, S. J., \& Lee, K. N. (2015). The effects of egoresilience, job stress, and efficacy of child care and teaching on sensitivity of infant teachers. The Journal of Eco Early Childhood Education \& Care, 14(3), 92-114.

Oh, J. Y. (2011). The analysis on the predicting variables affecting sensitivities of teachers in the early childhood education program. The Journal of Future Early Childhood Education, 18(3), 25-47.

Park, J. H., \& Rha, J. H. (2017). Exploring infant-mother and infant-teacher relationships as the precedents of infants' adjustments to childcare centers. Journal of Life-span Studies, 7(1), 17-35. doi:10.30528/jolss.2017.7.1.002
Park, S. J., \& Lee, K. O. (2019). Development and validation study on initial adjustment scale of infant's daycare center. The Journal of Korea Open Association for Early Childhood Education, 24(6), 101-126. doi:10.20437/KOAECE24-6-05

Seo, J.-E., \& Lee, S.-M. (2014). Influence of infant teachers' play beliefs upon teacher-infant interaction-Focusing on the mediating effect of play-teaching efficacy. The Journal of Korea Open Association for Early Childhood Education, 19(6), 129-150.

Seo, S. E., \& Park, S. K. (2020). The effect of children's interpersonal relations disposition and play patterns on the adjustment in childhood education institutions. Korean Journal of Early Childhood Education, 40(3), 179-197. doi:10.18023/kjece.2020.40.3.008

Seo, S. J. (2009). A study of influential variables on infant's adjustment behavior in early childhood education care settings: Emphasis on infant development, temperament, teacher-infant interaction, maternal beliefs about parenting and infant care as well as maternal support strategies on the infant's adjustment behavior. Journal of Future Early Childhood Education, 16(4), 259-288.

Shin, E.-S., Yu, Y.-E., \& Park, H.-K. (2004). Developing and validating an instrument to assess the relationship between kindergarten teachers' efficacy beliefs on play and their beliefs on play management practice. Korean Journal of Early Childhood Education, 24(1), 49-69.

Shin, N., \& Yun, H. J. (2016). Development of a teacher rating scale of childcare adaptation for infants and toddlers. Korean Journal of Child Studies, 37(6), 35-56. doi:10.5723/ kjcs.2016.37.6.35

Song, A. R., Song, S. M., \& Lee, S. (2015). The effects of infants' temperament, teachers' sensitivity, and mothers' separation anxiety on the infants' child care center adjustment. Journal of Life-span Studies, 5(1), 37-53. doi:10.30528/jolss. 2015.5.1.003

Song, J. S. (2004). A study on variables the related to children's adjustment in early childhood institution. Journal of Future Early Childhood Education, 11(3), 167-189.

Sung, M., \& Kim, J. (2018). Infant teachers' mathematical teaching initiative: constructivist belief and play teaching efficacy. The Korean Journal of the Human Development, 25(3), 37-50. doi:10.15284/kjhd.2018.25.3.37

Yang, S.-K., \& Moon, H.-J. (2010). The effects of maternal anxiety and the teacher-child relationship on the adjustment of 1 -and 2-year-old children in a child-care center. Journal of Korean Home Management Association, 28(2), 131-146.

You, J. Y., \& Hwang, H. J. (2015). Effects of the infant teachers' susceptibility, efficacy, and interactions between teachers and infants on the social-emotional development of infants. Journal of Korean Childcare and Education, 11(3), 1-23. 
doi:10.14698/jkcce.2015.11.3.001

Yun, J. M., \& Lee, J. Y. (2018). The influences of teacher efficacy on infant's adjustment to child care centers: The mediated effect of teacher-infant relationships. Journal of Korean Childcare and Education, 14(1), 203-225. doi:10.14698/ jkcce.2018.14.01.203

\section{ORCID}

Yoose Hwang https://orcid.org/0000-0002-0666-6861

Received December 31, 2020

Revision received February 27, 2021

Accepted April 6, 2021 